\title{
Public service broadcasting goes personal: The failure of personalised PSB web pages
}

\section{Jannick Kirk Sørensen}

MedieKultur 2013, 55, 43-71

Published by SMID | Society of Media researchers In Denmark | www.smid.dk The online version of this text can be found open access at www.mediekultur.dk

Between 2006 and 2011, a number of European public service broadcasting (PSB) organisations offered their website users the opportunity to create their own PSB homepage. The web customisation was conceived by the editors as a response to developments in commercial web services, particularly social networking and content aggregation services, but the customisation projects revealed tensions between the ideals of customer sovereignty and the editorial agenda-setting. This paper presents an overview of the PSB activities as well as reflections on the failure of the customisable PSB homepages. The analysis is based on interviews with the PSB editors involved in the projects and on studies of the interfaces and user comments. Commercial media customisation is discussed along with the PSB projects to identify similarities and differences.

\section{Introduction}

Traditionally, public service broadcasting organisations (PSB) among other obligations are expected to contribute to societal cohesion, nation building, formal and informal education and enlightenment. Almost from the beginning of broadcast, the physical propagation of radio waves has been constructed as an image of the ubiquitous dissemination of - and access to - its programming (cf. Scannell, 1989, 2005). The radio and later TV have typically 
been constructed as a common focal point for societies. The advent of multi-channel TV and radio, and particularly Internet services, has indeed challenged this classic image of PSB. It is thus interesting to analyse how PSBs embrace interactive media, and how they relate to the concept of public service media (PSM). Since the PSM concept encompasses quite different forms of media delivery and interaction, ranging from cross-media production and digital media asset management, digital distribution of live or on-demand programmes to games, wikis, user-generated content, communities and participatory platforms (cf. Moe, 2008; Lowe \& Bardoel, 2007), it is interesting to look at one the most radical departures from the classic notion of PSB, namely the customisable homepages of public service broadcasters. The media personalisation in theory makes it possible to match individual interests with content, but does it threaten the concept of "public" and the classic PSB remit of creating societal cohesion? On a normative level, the personalised public service web pages amplify some permanent tensions in the PSB construction between, to put in Reithian terms, giving people what they want, but also what they not thought they would like or find interesting. How do the PSB organisations in praxis relate to these questions in relation to personalisation? How were these questions interpreted in the design and functionalities of the personalised web pages? Using interviews with the PSB online editors directly involved, studies of the interfaces and user comments, this paper analyses the PSB personalisation projects. The services are subsequently interpreted in their specific media political contexts and related to similar projects provided by commercial media. Finally, the paper presents hypotheses regarding the lack of success for the personal PSB homepages.

PSB organisations' implementation of the customisable homepages can be understood as an example of the transformation from public service broadcasting to public service media. The concept "public service media" (PSM) has led to a comprehensive amount of scholarly work, for example in the texts by Scannell (2005), Murdock (2005), Lowe and Bardoel (2007), and Jakubowicz (2006), mainly analysing media political implications, consequences and potential in the concept of PSM, both on the level of PSB organisations (e.g., Petersen, 2008; Moe, 2008a), as well as new regulatory questions emerging (e.g., competition distortion issues) or the implications for the public sphere of PSM (e.g., Moe, 2008b). However, little has been written about the practical implementation of PSM in the PSB organisations, including the design challenges and editorial considerations that emerge when a PSB organisation offers new media services. In this, article our focus is on the relationship between users and PSBs seen from the editor's perspective, particularly focussing on how PSB web-editors approached the idea of customisation. What did the editors want to achieve with the customisable pages? What assumptions did they have about the user? And could the lack of success have been anticipated?

The starting point for this examination is not, as is the case in much of the PSB and PSM literature, the management level of the PSB organisation or regulatory issues, but rather a design perspective. With Krippendorff (2006), design is here understood as encompassing all levels of decision making in the creating of something new (e.g., a web service), including 
the discursive level, not just the graphical user interface. This analytical approach enables us to see how the customised PSB web services are the result of many, partly contradicting, objectives, as well as the result of the technical contingencies.

\section{Background}

During the last decades, public service broadcasters (PSBs) as well as commercial mass media have tried different ways to create what is often referred to as a "closer" or more "personal" relationship with the listener, viewer or user. Simultaneously, PSBs and other mass media construct different "segments" that can be targeted with different content (cf. Ang, 1991). Particularly when it comes to music, different tastes and preferences are difficult to accommodate with one channel, as Scannell $(1981,1989)$ observed. The idea of segmentation is however not new. Already in 1945 (and against the original visions of BBC's first Director General John Reith), the BBC introduced the BBC Light Programme and in 1946 followed with the $B B C$ Third Programme. Segmentation of radio and TV channels has now become the main trend, but still triggers media political discussions about the role of PSB as an agenda setter versus its role in the fulfilment of personal desires. With Internet technologies it is now technically possible to select the media content to match the smallest possible segment, namely a single user, a "segment of one" (cf. Peppers \& Rogers, 1993). As an example of this Negroponte (1995) suggested the concept of a personal newspaper: "the daily me". Subsequently, media personalisation technologies have caught the attention of both commercial media and public service media, as well as among many ICT engineers and programmers (e.g., Chesnais, Mucklo, \& Sheena, 1995; Ali \& van Stam, 2004; Velusamy et al., 2008; Ricci et al., 2011).

The media personalization literature discussing the implications, potential and problems of the technology (here represented by Fan \& Poole, 2006; Ho, 2006; Bredies, Joost \& Chow, 2007; Vesanen, 2007; Thurman, 2011) typically discerns between explicit personalisation, where the user or customer is actively involved (e.g., in customisation), and implicit personalisation, where algorithms and databases are the main actors, e.g., in algorithmic recommender services. Although one of the PSB organisations presented in this study also considered algorithmic recommendations of content (implicit personalisation), our focus in this paper is on the explicit type of personalisation. The personalisation of interfaces has its roots in different traditions, some outside the media field, e.g., work-oriented design of computer interfaces (e.g., MacLean et al., 1990) and mass-customisation of physical products (e.g., Victor \& Boynton, 1998), as well as in marketing (Peppers \& Rogers, 1993). This influences not just the conceptual understanding of personalisation, but also discourses of efficiency and automation affiliated with it.

Media personalisation technology is often presented as a technological response to the individualisation of northern European societies (Beck \& Beck-Gernsheim, 2002; Beck et al., 1997). It is often presented as an improvement of customer sovereignty (Moe, 2005; Rosen, 
2004), and of personal freedom and attention economy (cf. Mitchell, 2005). Huizingh (2002, p. 1233) speaks enthusiastically about web customisation as an example of "the shift from marketing being an agent of the seller to being an agent of the buyer". However, a more paternalistic information overload argument is also often forwarded, here by Malik and Fyfe (2012, p. 286):

\footnotetext{
"Due to the large amount of data on the internet, people often get so confused in reaching their correct destination and spend so much time in searching and browsing the internet that in the end they get disappointed and prefer to do their work using traditional means. The only way to help internet users is by providing an organized look to the data and personalizing the whole decoration of items to satisfy the individual's desire and in doing this the only way is to embed features of web personalization."
}

The quotation reveals a tension between the customer sovereignty argument and the automated selection of items presented. In the information overload argument, we observe an implicit assumption about media use being rational, goal-driven. This fits the internal institutional logic of media organisations focussed on quantitative consumption metrics, but as we will see, not necessarily that of the users.

In the literature, not only users but also media organisations are promised benefits of personalisation, typically in terms of increased customer loyalty, better exposure of products and marketing, better utilisation of "back catalogue" items (i.e., the long-tail argument introduced by Anderson, 2004), and increased knowledge on user's habits and interests (Peppers \& Rogers, 1993; Parsons et al., 1998, p. 37). Malik and Fyfe summarise the typical argument as: "Personalizing users needs is a much better way of selling items without wasting much time. This feature further pushes the sales ratio and helps merchants convince their customers without confusing them and puzzling them." They continue optimistically: "With the growing nature of this feature it is proved (...) that the era of personalization has begun (...)" (Malik \& Fyfe, 2012, p. 287). In this context, news items are also optimistically regarded as benefitting from personalisation (ibid., p. 287).

Within journalism studies and political studies focussing on the relation between media and democracy, the media personalisation concept with its programmatic declared shift from mass media to individually tailored media has received much attention. From a US perspective, Harper (1997) and Sunstein $(2001,2007)$ fear that personalised news might lead to weakening of society's democratic structure by limiting people's exposure to diverse and opposing viewpoints. In a European context, Helberger (2012) suggests that exposure to diversity should be approached from a user - or consumer - perspective. Sørensen (2011) discusses the potentials as well as the democratic problems in an individual-oriented provision of public service media content. Thurman (2011) observes that media personalisation triggers a number of debates concerning potential changes in news consumption, content diversity, the institutional and economic contexts for journalism, the journalist's role and the in editorial gate-keeping. He finds that "the mechanisms of personalization 
may increase content diversity in online news by taking away some of the control journalists have had over news selection" (ibid., p. 398), but notice also that explicit personalisation requires a user's time and effort. He questions thus how actively news users will engage in exercising the gained power over the news composition. Furthermore, Thurman (2011) sees a conflict between media providers' interests in controlling the brand experience via a specific mix of news and the idea of personalisation, as well as conflict between the promise of personalisation and the economy of scale in news production. Finally, he notes changed power relationships in editorial gate-keeping, with increased power to users (explicit personalisation) and algorithms (implicit recommendation). This influences the traditional role of journalists as "human information filters" (ibid., p. 400). The personalisation technology is thus expected to have an impact on many aspects of the journalistic praxis.

Through interviews with leading editors and content analyses of the personalised web services, Thurman (2011) and Thurman and Schifferes (2012a, 2012b) provide an overview of media personalisation activities of one PSB (BBC News) and ten private US and UK news providers (nine newspapers and one broadcaster). ${ }^{2}$ The authors look at both explicit and implicit personalisation, and they operate with a broad definition of personalisation that also includes email-services, SMS-alerts and RSS feeds. Two taxonomies based on examples are presented by Thurman (2011, pp. 398-399). The twelve interviews with editors conducted by Thurman between June 2007 and April 2008 show that the editors had positive attitudes and expectations regarding media personalisation, some even predicting that it would become "as big as blogging" (ibid., p. 408). There were however also reservations among the editors: Many believed that professional journalists still were required to ensure serendipity and quality of the personalised recommendations. Some feared for their professional identity, stating that "if there's anything we have it is our judgement about what people are interested in" or that "really good articles" might not be found by the users, if the article happened to be outside the user's filtering criteria (ibid., pp. 408-409).

Thurman's study does not explain the interviewed editors' role in the media personalisation projects. Thurman states that the "[i]nterviewees were selected on the basis of their position and availability" (ibid., p. 401). When we look at the titles of the interviewees we find one "Vice president", two "Head of", one "Managing Editor" and eight editors/assistant editors with unspecified roles in the organisation. Since it is unclear to what extent the editors were involved in the many different types of personalised services examined by Thurman (2011), it is difficult to tell whether editors' positions are based on their own experiences with personalisation technologies in their organisation, or if they are outsider observations. In our research, we not only interviewed content editors and editors in chief, but also four editors and one project manager directly involved in shaping the personalised PSB pages. A clear difference in positions can be seen by those editors directly involved in the projects and those observing. Another difference between the two studies is that while Thurman (2011) did not discern between PSB and non-PSB media, the present study closely focuses on PSB media. In relation to the regulatory- and policy-oriented debates 
on PSB organisations' Internet activities (e.g., Jakubowicz, 2007; Trappel, 2008; Moe, 2008c; Brevini, 2009; Löblich, 2012), it is interesting to examine whether PSB editors express different views on media personalisation compared to the ten non-PSB colleagues in Thurman's (2011) study.

\section{The case study}

Inspired by commercial web services like iGoogle, Netvibes and Facebook, a number of PSBs initiated around year 2006 projects to create customisable versions of their homepages or in some cases "My pages". In our study, we thus concentrate on two forms of explicit personalisation mentioned in Thurman's (2011, p. 399) taxonomy. The idea that PSB audience members - the visitors on the PSB webpages - can change the composition and content of the page is a radical departure from the classic notion of PSB as a mass media. In this article we analyse the customisable pages as an interpretation of the concept of public service media that emphasises customer sovereignty provided by digital interactivity. The customisable PSB webpages are thus interesting examples of how mass media with an editorial agenda approach the notion of customer sovereignty embedded in customisable interfaces. Considering this radical departure from the classic, editor-steered PBS webpage, it becomes empirically interesting to see how much customisation the PSB online departments actually offer to the users, and how. This is expressed through what we could call the degree of customisation. How are users made aware of the possibility to modify the page and its content? How much content (so-called widgets) can users choose from? How much freedom are they offered in changing the page-layout? The purpose of this article is retrospectively to analyse the meaning, implications and tensions created by the customisable PSB webpages in relation to different concepts of public service broadcasting, and to understand the personalisation in light of perceptions of PSB; does the PSB context produce different conditions for and expectations of media personalisation than in the context of commercial media? Are other values being emphasised through the design of the services and in the editors' statements?

\section{Method}

In a survey conducted by the author in December 2010, among the 106 homepages offered by the members of the European Broadcasting Union, nine cases of widget-based customisable webpages were found. ${ }^{4}$ Furthermore, two cases of check-box based customisable webpages were found, as well as 16 cases of homepages that used a layout imitating visual features of the customisable pages, such as content presented in boxes with rounded corners, but without offering any customisation functionalities. In this paper, we focus on homepages and "my pages" offering widget-based customisation. Widget-based customisation is characterised by direct manipulation of the interface, which instantly creates a new layout (cf. Shneiderman \& 
Maes, 1997). Using a framework derived from the academic fields of web usability and interaction design, the interfaces and interactive functionalities of the nine cases were analysed and categorised to identify different approaches among the PSBs to webpage customisation. Two typical and one extreme case were selected for further examination.

Secondly, semi-structured in-depth expert interviews (Kvale, 2007) were conducted with PSB online editors directly involved in customisation projects. Twelve interviews took place between May 2007 and March 2011 with the five editors directly involved in the design and development of the three services. As secondary sources, 25 PSB editors involved in or managing other new media projects were interviewed between May 2007 and February 2009 on the more general topic of personalised PSB. Using a snowball sampling technique, the PSB online editors were recruited via the annual Prix Europe festival in Berlin as well through the author's personal network.

The Mit DR project was followed from its start in April 2007 through interviews with its three consecutive editors: Jens Poder, Christian Valentiner and Mikkel Pagh. The editors of the BBC project (James Price) and the Mein WDR (Thomas Drescher) were interviewed retrospectively (March 2011 and November 2010, respectively) due to the confidentiality of the Mein WDR and BBC customisation projects. The interviews were subsequently coded in relation to topics and issues emerging in the first few interviews. Later, the interviews were analysed to identify re-occurring topics and positions on these topics. When empirically based conclusions are drawn, it is important to observe that the interviewees from DR in general expressed their views more boldly and directly than their colleagues from BBC and WDR. Also, the interviewees from DR revealed to a much larger extent details about the projects. This makes direct comparisons of the projects more difficult, but it offers insight into the different kinds of arguments that are mobilised by the editors. As a third source for evaluating the three customisable pages, users' comments posted on the blogs and web fora provided by the three projects to collect reactions, ideas, and general comments have been captured, coded according to reoccurring topics and subsequently analysed.

Below, the results of the interface analyses are presented, followed by a thematically organised presentation of the customisation editors' viewpoints. Finally, users' comments as well as editors' reflections on the failure of the services are presented and discussed, followed by a general discussion on PSB and media personalisation, and then conclusions.

\section{Content analysis of interfaces and their interactive functionalities}

An analysis of the interactive functionalities offered in the nine cases reveals a very broad interpretation of "customisation". The webpages can be categorised in three groups based on the degree of customisation they offer. Five PSBs offer a medium degree of customisation of their homepages: BBC (UK), SRR (Romania), RAI (Italy), RTV-SLO (Slovenia), BNR (Bulgaria). Two PSBs - TVP (Poland) and RTP (Portugal) - offer almost no possibilities for 


\section{Article: Public service broadcasting goes personal}

\begin{tabular}{|c|c|c|c|c|c|c|c|c|c|}
\hline Organisation & \begin{tabular}{|l|} 
TVP \\
Poland
\end{tabular} & \begin{tabular}{|l|} 
RTP \\
Portugal
\end{tabular} & \begin{tabular}{|l|} 
SRR \\
Rumania
\end{tabular} & $\begin{array}{l}\text { BBC } \\
\text { UK }\end{array}$ & \begin{tabular}{|l} 
RAI \\
Italy
\end{tabular} & \begin{tabular}{|l|} 
BNR \\
Bulgaria
\end{tabular} & \begin{tabular}{|l|} 
RTV- \\
Slovenija \\
Slovenia
\end{tabular} & $\begin{array}{l}\text { Mein WDR } \\
\text { Germany }\end{array}$ & \begin{tabular}{|l|} 
Mit DR \\
Denmark
\end{tabular} \\
\hline $\begin{array}{r}\text { Total degree } \\
\text { of } \\
\text { customisation }\end{array}$ & low & low & low & medium & medium & medium & medium & medium & high \\
\hline $\begin{array}{r}\text { Customisation } \\
\text { on }\end{array}$ & front page & front page & front page & front page & front page & front page & whole site & \begin{tabular}{|l} 
separate \\
page
\end{tabular} & \begin{tabular}{|l} 
separate \\
page
\end{tabular} \\
\hline $\begin{array}{r}\text { Default / total } \\
\text { number of } \\
\text { widgets }\end{array}$ & $15 / 15$ & $8 / 8$ & $15 / 15$ & $10 / 15$ & $10 / 21$ & $10 / 10$ & $71 / 136$ & $26 / 26$ & $0 / 210$ \\
\hline $\begin{array}{l}\text { Default page } \\
\text { for new users }\end{array}$ & yes & yes & yes & yes & yes & yes & yes & yes & $\begin{array}{l}\text { no, "start } \\
\text { packages" }\end{array}$ \\
\hline $\begin{array}{r}\text { External } \\
\text { content }\end{array}$ & no & no & no & no & no & no & no & no & $\begin{array}{l}\text { yes: } 143 \\
\text { widgets }\end{array}$ \\
\hline Extra widgets & no & no & no & \begin{tabular}{|l} 
yes, \\
catalogue
\end{tabular} & $\begin{array}{l}\text { yes, } \\
\text { catalogue }\end{array}$ & no & \begin{tabular}{|l} 
yes, \\
catalogue
\end{tabular} & no & \begin{tabular}{|l} 
yes, \\
catalogue
\end{tabular} \\
\hline $\begin{array}{r}\text { Number of } \\
\text { items in the } \\
\text { widget can be } \\
\text { changed }\end{array}$ & no & no & no & yes & $\begin{array}{l}\text { yes, in some } \\
\text { cases }\end{array}$ & yes & no & yes & yes \\
\hline $\begin{array}{r}\text { Removable } \\
\text { widgets }\end{array}$ & no & no & $\begin{array}{l}\text { yes, with } \\
\text { "X"-button }\end{array}$ & $\begin{array}{l}\text { yes, with } \\
\text { "X"-button }\end{array}$ & $\begin{array}{l}\text { yes, via the } \\
\text { catalogue }\end{array}$ & \begin{tabular}{|l|} 
yes, with " $X "$ \\
- button
\end{tabular} & $\begin{array}{l}\text { yes, with } \\
\text { "X"-button }\end{array}$ & $\begin{array}{l}\text { yes, with } \\
\text { "X"-button }\end{array}$ & $\begin{array}{l}\text { yes, in edit- } \\
\text { mode }\end{array}$ \\
\hline $\begin{array}{r}\text { Number of } \\
\text { columns }\end{array}$ & $1+1+1$ & $1+1$ & 3 & 3 & 3 & $1+1$ & 3 & $1+2$ & 2 \\
\hline $\begin{array}{r}\text { Type of } \\
\text { interface } \\
\text { feedback } \\
\text { indicating } \\
\text { customisation }\end{array}$ & none & \begin{tabular}{|l|} 
cursor \\
changes \\
when over \\
triangle \\
buttons
\end{tabular} & none & \begin{tabular}{|l|} 
cursor \\
changes \\
when over \\
widget head \\
+ display of \\
border
\end{tabular} & \begin{tabular}{|l} 
cursor \\
changes \\
when over \\
widget head
\end{tabular} & \begin{tabular}{|l|} 
cursor \\
changes \\
when over \\
widget head
\end{tabular} & \begin{tabular}{|l|} 
cursor \\
changes \\
when over \\
widget head
\end{tabular} & \begin{tabular}{|l|} 
cursor \\
changes \\
when over \\
widget head
\end{tabular} & \begin{tabular}{|l|} 
cursor \\
changes \\
when over \\
widget head
\end{tabular} \\
\hline $\begin{array}{r}\text { Movable } \\
\text { widgets }\end{array}$ & $\begin{array}{l}\text { Push up and } \\
\text { down within } \\
\text { same } \\
\text { column }\end{array}$ & $\begin{array}{l}\text { Drag-n-drop } \\
\text { within } \\
\text { column }\end{array}$ & $\begin{array}{l}\text { Free drag-n- } \\
\text { drop }\end{array}$ & $\begin{array}{l}\text { Free drag-n- } \\
\text { drop }\end{array}$ & $\begin{array}{l}\text { Free drag-n- } \\
\text { drop }\end{array}$ & \begin{tabular}{|l|} 
Drag-n-drop \\
within \\
column
\end{tabular} & $\begin{array}{l}\text { Free drag-n- } \\
\text { drop }\end{array}$ & $\begin{array}{l}\text { Drag-n-drop } \\
\text { within same- } \\
\text { sized } \\
\text { columns }\end{array}$ & $\begin{array}{l}\text { Free drag-n- } \\
\text { drop }\end{array}$ \\
\hline $\begin{array}{r}\text { Collapsable } \\
\text { and } \\
\text { expandable } \\
\text { widgets }\end{array}$ & no & no & $\begin{array}{l}\text { Yes, with } \\
\text { triangle } \\
\text { button }\end{array}$ & $\begin{array}{l}\text { Yes, with } \\
\text { triangle } \\
\text { button }\end{array}$ & $\begin{array}{l}\text { yes, with } \\
\text { special } \\
\text { button }\end{array}$ & \begin{tabular}{|l|} 
Yes, with \\
triangle \\
button
\end{tabular} & no & no & $\begin{array}{l}\text { Yes, with } \\
\text { triangle } \\
\text { button }\end{array}$ \\
\hline Edit button & no & no & no & $\begin{array}{l}\text { yes, some } \\
\text { widgets }\end{array}$ & no & yes & $\begin{array}{l}\text { yes, some } \\
\text { widgets }\end{array}$ & $\begin{array}{l}\text { yes, some } \\
\text { widgets }\end{array}$ & $\begin{array}{l}\text { yes, all } \\
\text { widgets }\end{array}$ \\
\hline $\begin{array}{r}\text { Display mode } \\
\text { of the widget } \\
\text { content can } \\
\text { be changed }\end{array}$ & no & no & no & no & no & no & no & no & yes \\
\hline $\begin{array}{l}\text { Colours can } \\
\text { be changed }\end{array}$ & no & no & no & yes & yes & no & no & no & yes \\
\hline $\begin{array}{r}\text { Title of widget } \\
\text { can be } \\
\text { changed }\end{array}$ & no & no & no & no & no & no & no & no & yes \\
\hline $\begin{array}{r}\text { "Reset to } \\
\text { editor default" } \\
\text { button }\end{array}$ & no & yes & no & yes & yes & yes & yes & yes & no \\
\hline
\end{tabular}

Table 1: Degree of customisability of nine customisable PSB webpages, cited from: Sørensen, 2011 
customisation: The content modules (widgets) can just be moved within the same column, not removed, collapsed or edited. In the other cases, widgets can be moved and modified more freely, as well as they can be removed. The number of widgets varies also among the pages: RTP has only 8, whereas RTV-Slovenia offers 136 and Mit DR (Denmark) 210 widgets. In the two latter cases, as well at BBC and RAl, the extra widgets are presented in a catalogue. In all cases, except Mit DR, the content of the widgets mirrored that of classic PSB content categories.

Two PSBs offer customisation on a separate "My page" while maintaining the homepage non-customisable, namely Mein WDR (Germany) and Mit DR (Denmark). Where Mein WDR presents a copy of the non-customisable front page with limited possibility for customisation and with relatively few widgets (26), Mit DR stands out with a completely different approach to customisation. ${ }^{5}$ With 210 widgets, the customisability is much higher than in any of the other cases. More surprisingly, a large percentage (68.1\%) are RSS feeds from external sources like other Danish media and web services. ${ }^{6}$ Furthermore, Mit DR offered the functionality for creating several customised pages as well as the user's own widgets based on RSS-feeds. Finally, the Mit DR "My Page" service was introduced to new users in an unusual way. The editorially suggested widgets were organised thematically in so-called "start packages" named, e.g., "The Family Package", "The Life Style Package", "The Sports Package", "The News Package" or "The Nerds Package"? This makes Mit DR an unusual case among the customisable PBS pages.

Now, the question emerges concerning the reasons for Mit DR's quite different appearance. Answers to this are sought through interviews with the editors involved in the design and implementation of the services. To compare these, editors involved in creating two comparatively typical cases, namely the Mein WDR "my page" and the BBC customisable homepage, are interviewed on their positions regarding their respective services as well on the functionalities offered by Mit DR.

\section{Editors' positions on customisation and media personalisation}

The editors' design deliberations, presented below, reveal that the customisable homepage projects were situated in an organisational and media political environment full of contradicting objectives. The customisable pages should simultaneously provide users with a higher degree of freedom to choose what they wanted to see, but they should also reflect one of the classic PSB purposes, namely to introduce users to what they did not know they would find interesting. The pages should help expose more of the PSB web content, but also (at least normatively) let a user be more in charge of his or her attention economy (cf. Simon, 1971; Mitchell, 2005). The pages should ensure continuous amounts of traffic (visitors) on the PSB pages, in a web market with growing competition, but the pages should not be perceived as anti-competitive by commercial web services and content providers or as a thread internally in the PSB organisation. There are thus permanently two perspectives 
present in the editors' considerations: one which relates to the translation of the discussion of the distinctiveness of the public service media programming into the field of customer sovereignty, and one which relates to the reach - and thereby the popularity - of the PSB services. While these two dimensions of public service broadcasting have framed media political discussions for years (cf. Nissen, 2006), I claim that the discussion is intensified in the area of public service media when a customer sovereignty argument is forwarded as strong as it was in the cases of customisable web pages. In the following, I will thus discuss the customisable webpages according to these two perspectives.

\section{The distinctiveness perspective: user sovereignty versus agenda setting}

The PSB homepage typically receives very heterogeneous groups of users. In contrast to radio or TV channels that often are shaped around a group of topics, segments or a lifestyle, the PSB front page serves typically as the portal entry to the whole site, providing a general information architecture for the site. The space however is severely limited on the front page both in terms of the number of items, e.g., news, that can be shown and in terms of links or menu buttons that can be displayed. The information architecture should thus both satisfy a user's search for specific information, as well as provide a good overview of the diversity of content that the PSB has to offer. This display of diversity is not only part of making the webpage valuable to the user, but is also part of the public service mission. When the concept of user-driven customisation is introduced in the context of PSB web pages, the tension between user sovereignty and agenda-setting/editorial recommendation stands out as very visible. How did the different editors relate to this question, and how did they motivate the design decisions taken in relation to the personalised pages?

In the research interviews, the editors all stated that one of the main purposes of the customisable PSB webpages was to help solve the classic information architecture problem of PSB homepages. For editor Thomas Drescher from WDR, the customisable webpage is an attempt to react to the situation that the WDR editors "in many cases don't know at all what the user expects from our web pages" (interview, Nov. 11 2010, my translation). In this way, he forwards a customer sovereignty/co-design argument for the page. Editor James Price from the BBC puts more emphasis on the exposure of the PSB content, stating that the purpose was to "try to find a mechanism that could broaden things out so people would in large measure go to other parts of the site; to get people deeper into the site, quicker and more easily" (interview, March 25 2011). Here, the objective is slightly more focussed on the organisational interests. Mit DR's first editor Jens Poder also follows this line of argument, focussing on the exposure and "stickiness" of webpages, hoping that social recommendation will increase exposure: "Mit DR.dk in the first place is about making that content available - when one user has found something it becomes visible for other users when published on his page" (Poder, interview, Nov. 13 2007, my translation). As this interview from the initial stage of the Mit DR project shows, the individual Mit DR 
pages were originally planned to be visible to other users. The social sharing idea was the main driver in the beginning of the Mit DR project, since the project originated from a wish to renew DR.dk community pages for youth, called "SKUM". The social sharing idea was an early attempt to fulfil the function that, e.g., Facebook later was to cover, however with a focus mainly on DR content. In this sense, the early vision for Mit DR could also be seen as a strategic initiative to create more traffic on the DR.dk site by encouraging users to exchange and discuss DR content. In light of the two-year delay of the Mit DR project, and the success of social network sites in the same period, the second editor, Christian Valentiner, abandoned the idea.

As noted above, the space available on the PSB front page is limited, and thus heavily contested among the different content producing departments in the PSB organisations. In line with the customer sovereignty argument, but also to avoid involving the PSB web-department in this organisational struggle, editor Thomas Drescher suggested: "Why should we discuss with the radio- and TV producers about what people out there want? Leave the decision to them!" (interview, Nov. 30 2010). Jens Poder at DR in the same way sees Mit DR as a way to counter what he sees as a paternalist attitude toward users, listeners and viewers within the PSB organisation:

\footnotetext{
After all, no users are interested in a playpen-attitude: "Welcome to our isolated internet world where we are the gatekeeper on what is published". It is not a media where there is a Mr. News sitting at the news desk saying "Good Evening. This is the truth about the truth and my name is Sven-Erik News, and this is how the world was today." (Poder, interview, Nov. 132007 , my translation)
}

Conversely, BBC presented a relatively large non-customisable content box - the "Main Feature Box" on the customisable homepage. The users of the beta-version of the site reacted generally very negatively to this feature: 88 of 388 user comments posted on the $\mathrm{BBC}$ blogs dedicated to the project were negative or even hostile. Only 3 comments were positive regarding the "Main Feature Box". ${ }^{8}$ Reacting to strong negative comments, editor James Price argued for the Main Feature Box as an "anchor" for the design that serves the same purpose as a strong image on the front cover of a printed magazine. He also argued that "the BBC should have at least one place to display what we reckon is important, interesting or entertaining. Our mission isn't simply to air stories and programmes we know you wanted... but also the ones you didn't know you wanted. The promo [the main feature box] is our chance to inject a dose of serendipity". . The harsh debate around the BBC's "Main Feature Box" reveals the central ambiguity of the customised PSB homepage: Is it the user's page or the broadcaster's page? In the BBC case, this question became pressing, since the customisability of the page suggested a user sovereignty that however was impeded.

DR and WDR instead presented a customisable "my page", and felt no reason to make specific content obligatory. At Mein WDR, it was possible to remove all content from the page, leaving just an empty page. At Mit DR this was also possible, as well as having a page 
consisting only of non-DR content. While an empty page is not interesting for the journalistic discussion of exposure of diversity or for the media political discussion of position of the PSB as a pluralistic content recommender, editor Valentiner expressed some concerns that a complete free choice, also of external content, would threaten the PSB mission:

\footnotetext{
Where do we stand as a public service institution if we let go of everything, say that everything is "pull" and let users steer everything? What role would we have? Where should we make an effort to still make the narrow content? How does the narrow content get into the picture? (Valentiner, interview, June 11 2008, my translation)
}

In another research interview, he reported that some editors-in-chief from the content producing departments expressed concerns about the lack of the "narrow" DR content, e.g., culture, in Mit DR. However, he sees Mit DR conversely as an opportunity for exposure niche content (Valentiner, interview, Jan. 15 2009). In the Mit DR project, PSB agenda-setting was thus radically downplayed.

\section{The reach perspective: mass-media customization?}

Web customisation as well as other personalisation technologies are typically presented to users as tools for improving their customer sovereignty. This argument was also forwarded in the texts introducing new users to Mit DR and BBC. In the critical literature on media personalisation, the customer sovereignty argument is however countered with arguments of surveillance and commercial control (cf. Parks, 2004; Carlson, 2006). The context of this research however has been commercial media and content aggregators. It is thus not surprising if customisation, micro-casting and media personalisation here are used to increase the consumption of the content and collect information on user habits. But how do the case study PSBs react to this question of balancing the assumed user-interest of sovereignty with possible interests of creating predictable audiences? How do they balance the promise of an individual media service with organisational interests?

During the design process, DR web editors construed the typical PSB user as ephemeral and picky (e.g., Poder, interview, Nov. 13 2007) and as a customer-king that should be served (cf. Heide, interview, May 29 2007; Valentiner, interview, Jan. 15 2009). One of the untraditional means was the inclusion of content (RSS-feeds) from other media, including feeds selected by the user. The external content represented a considerable part of Mit DR: 68.1\% of the RSS-feeds in Mit DR catalogue originated in sources outside DR ( $n=210$ as of 31-01-2010)..$^{10}$ Editor Valentiner explained that the external content was chosen among the top 100 .dk publicist web sites, as well to supplement DR's content in areas where DR is not strong. Editor Valentiner explained that composing the content for Mit DR is a matter of finding "the best way of keeping our customers in the shop". He asks rhetorically: "Is it by forcing them to only use our content or is it by giving them the best possible array of content?" (Valentiner, interview, Jan. 15 2009, my translation). The large amount of external 
content could be justified by one of DR.dk's official strategic goals 2007 - 2010, namely to "serve as the population's guide to media and culture" (DR, 2007). But the external content also reflects that the classic PSB gate-keeper function here has been discarded in favour of a strategy to create more traffic at the site. The goal seems rather to keep up the number of visitors at DR.dk at a time when the PSB editors expected Facebook and other social media to weaken DR.dk's position as one of the .dk sites with the most visitors. ${ }^{11}$ This is supported by editor Poder's statement at the kick-off meeting for Mit DR, on November 13,2007 , that one of the purposes was to "re-create dr.dk in the web 2.0 market" (personal notes, November 2007).

Another untraditional means was to use a commercial customisable content aggregator, Netvibes, as a blueprint and inspiration for the visual design of the interface, the interaction design, as well as for the functionalities. While the other customisable PSB pages present the editor's default choice to a new user, Mit DR presents target-group oriented "start-packages", own feeds, multiple pages, and catalogue view inspired by the commercial web-aggregator service Netvibes. This inspiration is confirmed by the editors Poder and Valentiner. It was thus reported that meetings had taken place with Netvibes staff.

The Mit DR plans for the external content were even more far-reaching than RSS feeds. Originally they included a YouTube player and a popular music streaming service - Last. $\mathrm{fm}$. In a research interview, DR online editor Niels Prætorius expanded the argument for external content:

\footnotetext{
Interviewer: If we think a bit ahead, it would then in principle be OK for you if I could get my Google mails displayed on my Mit DR page through a widget?

Prætorius: Yes of course! Let's assume for a moment that I am a cynical businessman - we could do so just for fun - my plan could very well be: the more Danes or users in general I could get to administrate their lives on the web with my [DR's] top-bar on it, the more satisfied I would be. (Prætorius, interview, June 19 2008, my translation)
}

Due to a mix of project delay and legal problems, the YouTube and Last.fm widgets were abandoned, as well as other non-RSS based external content. What is noteworthy here is the strategic perspective of getting as much web-traffic to visit DR.dk even if the purpose for the user's visit is private, like checking an email. Other interview statements are also illustrative for the triple agenda of delivering a customisable service while also maintaining the position of DR.dk in the Danish web market and exposing DR's content to users. Editor Poder:

DR.dk is a traditional site: At one point someone sat down and thought up a hierarchical information architecture of sections and sub-sections and sub-sub-sections. This makes it extremely difficult for the users to find the content. We have more to offer than most users' experience. It's a pity that we don't get the great content utilised optimally. We don't get it out to enough Danes. (Poder, interview, Nov. 13 2007, my translation) 
What is interesting here is the consumption and mass-media perspectives: the content should be "utilised" and should "get out to enough Danes". The customer sovereignty and the construction of the picky and ephemeral users step in the background. Also, when content for Mit DR is selected, it is a mass media perspective that is applied. When editor Valentiner planned the content for Mit DR, he used DR's segmentation of the mass media audience. The segment-oriented thinking is also represented in the composition of the "start packages". Editor Valentiner:

To spell it out: Which stereotypes do we think will use the site? We have the "blue type": sports, news, money, and we have a popular music [P3] profile, and we have a female segment. Those are the types [of users] that we outline to cover as broad a share of users as possible (...) We have prioritised to target these groups. (Valentiner, interview, June 11 2008, my translation)

These statements and design decisions indicate that the editors of Mit DR aimed for maximising the number of users, downplaying the PSB agenda-setting. The perspective on users remained thus, despite the concept of customisation, at mass media centred perspective. At the BBC, external widgets, like an email-reader or custom RSS-feeds, were also considered in the design phase, but later abandoned. Editor James Price explained: "I think as a product it would have made the page better and a lot of people would have liked it but it was felt that it was, yes, anti-competitive" (Price, interview, 2011-03-25). At WDR, editor Thomas Drescher finds it "strange" [seltsam, komisch] that a media content producer would include the competitor's offers in the display. He makes a clear distinction between content aggregators like Google and Netvibes and publishing media like WDR (Drescher, interview, Nov. 30 2010).

The different media political environments in Germany, the UK and Denmark possibly have had an impact on how the editors designed the customisable web services. In Germany and in the UK, public service providers for a long period of time have faced heated debate and criticism from commercial media and their lobby organisations for distorting competition (see, e.g., Löblich, 2012; Graf, 2004), a criticism that led to the introduction of public value tests and explicitly made the editors of the customisable webpage very careful in the design of the services. Yet the situation in Denmark has been different. A "value test" [værditest] was introduced in the Danish public service contract 2007-10 (DR \& Kulturministeren, 2006), but the Mit DR project was not tested for its public value, nor were any of the editors discussing the public value issue in the interviews conducted. An organisational focus on increasing quantitative performance in terms of consumption and visiting users provided, in the case of DR, the path for the wide interpretation of PSB customisation. Conversely, at Mein WDR, the quantitative performance was not important, but rather seen as a threat. If the service would become too popular, it could be criticised by private media for distorting the competition (Drescher, interview, Nov. 30 2010). In the same manner, the customisable BBC homepage carefully balanced between the PSB agenda and 
possible accusations of being anti-competitive. The conditions for the customisation projects were thus different. The media political conditions for testing a more far-reaching concept of web-customisation of PSB pages were thus better in Denmark, than in Germany and the UK.

\section{Beta-users' reactions}

All three services provided users with opportunities to post comments or report problems via weblogs. ${ }^{12}$ In the case of the $\mathrm{BBC}$, the weblog closed for new entries as the customisable page changed status from a page under development (beta-version) to becoming the main homepage. The commenting on Mit DR and Mein WDR were kept open during the projects. Of the 1,693 comments in all three services, 932 must be described as being off-topic. Mit DR received the highest amount of off-topic comments (82\%); our analysis indicates that the Mit DR webfora served as a "catch-all" address for comments on the purpose and praxis of the programming or technical problems with other online services provided by DR. At the BBC, just $1 \%$ could be described as off-topic, at Mein WDR $17 \%$. Of the ontopic comments, Mein WDR received the highest percentage of positive comments (55\%), whereas the BBC had the lowest (26\%).

BBC, $n=388$

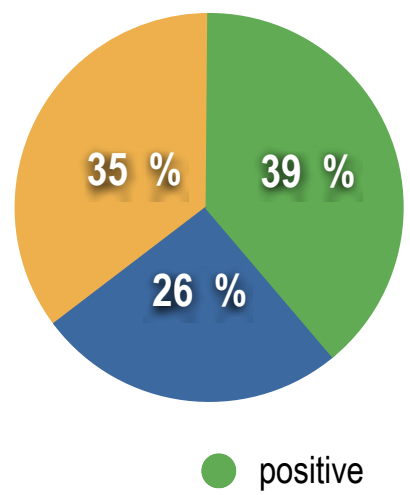

Mein WDR, $n=125$

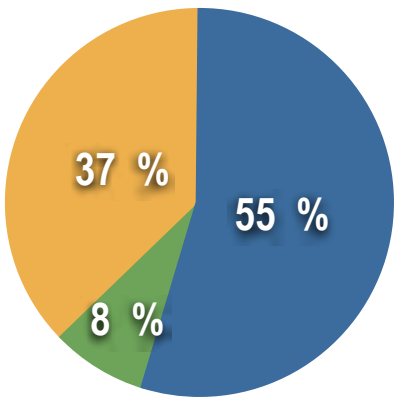

negative
Mit DR, $n=193$

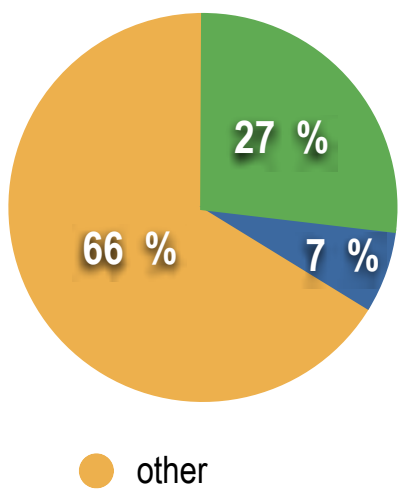

Table 2: Distribution in percentage of positive, negative and "other" comments on the three customisable pages of BBC, Mein WDR and Mit DR. Source: Sørensen 2011

The many negative comments to the BBC beta-version page considered mainly the Main Feature Box, as discussed above, but also the graphic design and the brand experience. The new layout made the BBC homepage look like a toy, many argued. These issues were neither prominent in the cases of Mein WDR nor Mit DR. If we look at the positive comments on all three services, they welcomed the idea of customisation. Typically, beta-users called even for more flexibility and customisation, but stressed also that their comments were based on a first impression. The BBC editors replied to the comments on a general level not addressing specific users, whereas Mein WDR to a certain extent replied to individual users. The Mit DR editors did not reply to a noticeable degree to comments, neither on-topic, nor off-topic. In an 
interview on January 24, 2011, editor Pagh admitted to have forgotten to look into the comments for a long period. The large percentage of comments in the category "other" at Mit DR (66\%) is due to the many technical problems with the service. See (Sørensen, 2011) for details on the survey.

\section{User demand and uptake}

In quantitative terms, the three customisable pages were not a success. At the BBC, only around $10 \%$ of the users changed the default layout, editor Price estimates (interview, March 25 2010). Mein WDR editor Drescher is not allowed to mention exact figures, but stated that the number of daily users "remained in a three digit range" - a fraction of the number of users at the WDR.de site in general (interview, Nov. 30, 2010). The use of Mit DR was also very modest - in the period from December 2009 to October 2010, only $0.09 \%$ of the visits at DR.dk went to Mit DR. The Mit DR editors expected 200,000 user profiles to register, but only around 12,000 signed up. Apparently, the form of customisation (homepage customisation or "my page") did not play a determining role: a highly customisable "my page" like Mit DR did not become more popular than the less customisable "my page" like that of Mein WDR. A very exposed page like the BBC front page did not turn more users to customisation. Looking back at the now discontinued customisable BBC page, James Price reflected on the lack of success.

\footnotetext{
Clearly, in the new world, online people are much more used to selecting what they want, but at the same time I think it is becoming increasingly clear that the job of editors is not redundant. It is a job to sift through information, select it and package it up, present it in a way that is immediately consumable and easy to use. Honestly, looking at user testing of the BBC homepage, people don't want twenty-eight different news sources and construct their own vision of what the news agenda is. They actually quite like the fact that they can come to a service like the BBC or one of the newspapers. (Price, interview, March 25 2010)
}

Conversely, editor Thomas Drescher from WDR reported about mostly very positive comments at the above mentioned blog-website, but concluded that the amount of daily users simply was too small to sustain Mein WDR, although he also stated that the WDR online department has no quantitative targets in terms numbers of visitors or page views. Mein WDR was conceived and presented as an experiment for the WDR online editors to gather experiences with personalisation. Drescher believes that users rather want a prioritized preselection of news (Drescher, interview, Nov. 30 2010).

At DR, a third editor, Mikkel Pagh, became in charge of Mit DR before the decision was taken to discontinue the development and maintenance of the web service. Reflecting on lack of quantitative success, Pagh pointed at the high level of granulation as a problem: users were forced to decide on a very detailed level of what information they would subscribe to. But, as he stated, very few people are either $100 \%$ or $0 \%$ interested in, e.g., ice hockey. Broader categories of content may better reflect the interests of the users. This observation 
possibly explains why users only in a modest degree customised the seven start-packages. Pagh also observed that visually, the news items at Mit DR are not emphasised editorially according to relevance. They are just listed chronologically as RSS-news feeds. According to Pagh, this chronological list does not make the service useful. The promise of Mit DR to users to "Get you own news overview fast" was actually not fulfilled, Pagh concluded. Regarding the discussion of editorial agenda-setting, he stated that "we are not really interested in what matters for us, more for those that use the site". He still supports the idea of the external content because "we are one of the few media [in Denmark] that has the opportunity to do this". The purpose, according to Pagh, was to present the same basic RSS functionalities like Netvibes and iGoogle but in a less nerdy way and in Danish language. Regarding the purpose of increasing the time spent by visitors of DR.dk compared to what Pagh described as the competitors, he stated that "DR.dk is very focussed on reach since we are financed by licences" (Pagh, interview, Jan. 24 2011, my translation).

\section{Discussion}

The customisable PSB pages can be discussed in two ways: as examples of customisable homepages or "my pages" provided by news organisations, and as examples of personalised public service media. They can be discussed from both the strategic-managerial perspective of the media organisations as well as from the "user's perspective". The existing PSM literature provides extensive discussions of the high level media political, regulatory, and PSB organisational-strategic issues emerging in the transition from PSB to PSM (cf., e.g., Picard, 2012; Brevini, 2009; Trappel, 2008; Moe, 2008a, b, c; Mortensen, 2008; Jakubowicz, 2007). This paper instead examines a case of PSM in praxis, leaving the high-level discussions of PSM in the background. Obviously, the regulatory, media political and organisational contexts play a role in the shaping of PSM projects, but the main purpose of this paper is to examine how the customisation is constructed by the editors balancing between different sets of objectives.

Seen as PSM projects, the customisable webpages may not seem important since they constitute just one (failed) experiment in the transition from public service broadcasting to public service media, but as experiments in the re-interpretation of relationship to audiences, the customisable pages constitute however an important experience: They tested the concept of making the user the editor. The customised pages are just one of many different ways in which media companies, including PSB organisations, attempt to involve users in the creation or selection of the media content. Bakker (2012) presents a retrospective overview and a critical analysis of media companies' strategies of implementing usergenerated content (UGC). But parallel to our findings, he concludes that to a large extent, media companies' expectations of a higher customer loyalty, more quality content and lower editorial cost were not met despite high expectations among editors. 
In the beginning of this paper, we questioned whether the idea of 'public' in terms of the public sphere would be threatened by media personalisation. The question has been discussed on a general level - from the perspective of media landscape dominated by commercial media - by Sunstein (2007). Here we more specifically wanted to examine whether "public" as in "public service broadcasting" and "public service media" is threatened, as discussed by Scannell (2005) or Moe (2008b). Discussed normatively, the customisable pages are a departure from the notion of "public" as in broadcast. One can argue that customisation is a natural step in the process of segmentation of content towards different target groups and interests, a process that has taken place for decades through segmented channels and narrow cast, but on the other hand customisation represents a promise of an individually centred filtering of content. Normatively, customisation is thus a challenge for community building agenda-setting, as PSB historically has been conceived, but as, for example, Syvertsen (2003) and Bolin (2004) observe, PSB concept changes with its time and in response to the society in which it is situated. In praxis, customisation does not provide a radical new interpretation of PSB. The actual implementation of PSB customisation did not change the PSB content provision fundamentally. In most cases, only few and relatively broad categories of content were offered in the widgets. These are typically identical with the classic content categories of the PSB, leaving few possibilities for a radically different composition of the PSB offer. An exception is Mit DR. The editors Poder and Valentiner presented the project as an antithesis to editorial gate-keeping, as a customer-oriented democratization of DR (cf. also interviews with Heide and Prætorius). Particularly editor Poder projected an image of a paternalistic news organisation that needed to be countered with interactive tools controlled by users. Their vision of free choice however was not echoed among users; to a large extent they did not modify the content packages recommend by the editors or did not use Mit DR at all.

This leads us to the second perspective, the user-provider relationship. This perspective implies some kind of construction of the "user" and the "user needs". As McHardy (2009) observes, the "user" is in many cases a make-shift construction made by designers or marketing people to support their visions. In our case, we must thus rely on images of the user constructed by the interviewed editors. Luckily, these images can be supplemented and contrasted with the help of the analysis of user-comments provided in the abovementioned web fora, with quantitative data about the traffic of the customisation services, and with analyses of the interfaces and functionalities.

The reasons for the discontinuation of the customisation can be constructed on a practical, case-based level, where the projects are seen as just examples of the general idea of media personalisation, or it can be taken as an indication of a more fundamental problem with media personalisation. If we first look at the case-based level, it can be observed that the customisation served different purposes in the three cases, and thus had different success criteria. At the BBC it was conceived as an additional feature of the new homepage layout (cf. "A Lick of Paint" blog comment by editor Richard Titus, Dec. 13, 2007). ${ }^{13}$ Later it 
was mobilised to increase the exposure of depth of the BBC site. Mein WDR was an experiment that was to give online editors more experience with personalisation. Mit DR was to serve many purposes, as both a solution for content congestion at the DR.dk home page, as a tool for the re-launch of DR's youth community "SKUM", as a generic technical framework for the vision of a decentralisation of web content production, as a leverage for the introduction of a single-sign-on user-login system for DR.dk, as an internal showcase for the DR Interactive production department, and as an internal statement in favour of customer sovereignty and interactivity, against broadcast thinking, the latter argument particularly forwarded in the early interviews with editor Poder (May 32007 and Nov. 13 2007). In the case of Mit DR, it can be speculated whether the many different objectives played a role in the delay of the project, for its lack of technical stability and for the low uptake of the service. The lack of popularity in the case of Mein WDR could be explained by the experimental status of the project as well by the media political situation for German PSB organisations that enforce restrictions on the provision of Internet services. Editor Drescher indicated that a too popular Mein WDR service could have caused criticism from commercial media. The lack of success in the case of the customisable BBC homepage is more difficult to explain. As the main landing page, it is well exposed to the users, and the features of customisation were well announced in the interface and in texts. In this case, as editor Price indicated, the lack of added value might be the reason for users not to customise. This leads us to search for explanations on a more general level.

Discussed as customisable news homepages and "my pages", we can observe that also among private media organisations, the customisable homepages as well as the "my page" have been discontinued. Thurman (2011, p. 407) observed a "significant growth" of homepage customisation among the eleven media webpages examined in the study, although a decline in "my pages" (ibid., p. 407). In the latest sampling (October - December 2010), presented in (Thurman \& Schifferes, 2012a) five of the eleven media offered a customisable "my page" and six "homepage customisation" (ibid., p. 782). ${ }^{14}$ In our own survey of the same eleven pages, conducted July 2013, none of the "my pages" or customisable pages are online. In the cases of the customisable PSB web pages presented in this paper, five are discontinued (BBC, Mein WDR, TVP, RTP, RAI) and one no longer maintained (Mit DR). The three remaining (SRR, BNR, RTV-Slovenia) were still online when visited in July 2013. Although we do not know in all cases the reason the services were discontinued, it indicates that the problems for customisable homepages and "my pages" are not limited to PSB.

Thurman (2011) observes that "[i]n its explicit form [i.e. customisation], personalization demands time and effort from users" (p. 397). If we apply this to the customisable pages, we can assume that the time and effort needed typically by users are expected to be outweighed by improvements, e.g., an easier interaction or, as marketing literature phrase it, a better attention economy (Mitchell, 2005). One way of understanding the lack of success would thus assume that the services did not deliver a convincing argument to users to initiate customisation or did not in the long run deliver an improved service for those who 
received the customisation enthusiastically, e.g., in user blog comments. This would be a performance oriented cost/benefit understanding, which would call for improved technical solutions, e.g., automated user-profile based content recommendation (implicit personalisation). Another way of understanding the lack of success would pay more attention to the nature of the human activity of media "consumption" or "use"; the act of looking for and reading/seeing/listening to novel media content, like news. Here many other explanations than just a cost/benefit view might be interesting.

As reasons for the failure, the PSB customisation editors point in their retrospective reflections at some properties of the traditional news webpage missing in the customisable pages: the agenda-setting, the gate keeping and the visual presentation (layout). In the theoretical literature we find support for this view. Schoenbach (2007) develops the theory of the "reliable surprise" as a measurement for a meaningful media experience. With Huizinga (1955) and Moles (1968), he observes that humans search for pleasant surprises that challenge expectations, but only to a certain extent and with a certain degree of aesthetic complexity. Klapp (1986, p. 199) presents in the same line of thought four categories of information: "good (functional) redundancy", "boring redundancy", "boring variety" and "good variety". Assuming that users strive for "good (functional) redundancy" or "good variety", and assuming that the configuration of the customisable page would require the user to invest time and attention in this new option, the conclusion follows that customisation only has value to the user if editorial selection - the agenda setting - is not satisfying the user. If content editors do their job well in constructing narrative value (Sørensen, 2011), the case for media personalisation is weak. The hypothesis is thus that the non-personalised good (functional) redundancy, or good variety is more attractive to the user, despite its possible irrelevant or less interesting stories, than a highly specialised, customisable page with little redundancy. The non-personalised mix of news and content appears to be more attractive than a personalised, filtered mix.

In the interviews made in the initial phases of the project, the Mit DR editors provided very institution- and performance-oriented objectives for the Mit DR project. It should increase the exposure of the content and ensure DR.dk a position in the web 2.0 market. At the BBC the same objective was proposed, however in a milder form. At Mein WDR, quantitative success was an objective, again due to the media political environment, but here the project should ease the internal pressure on editors of WDR.de for exposure on the homepage by using a customer sovereignty argument. If we want to trace the logic behind the projects, it appears thus that a clash took place between two understandings of the users' purpose for using news services. The one, promoted by the online editors as starting points for the projects, assumed a very picky and highly rational media user who wanted to protect his or her attention economy as best as possible, e.g., by using customisation and filtering. This view also was supported by most user comments at the weblogs mentioned above and by ICT engineers interviewed for this project (e.g., Stockleben and von Sprechelsen). This understanding fits well with a performance-oriented culture, and with the 
construction of ICT as a tool for customer sovereignty and individualism. The other understanding, that users prefer editorial recommendations, however gained momentum due to the lack of success for the customisable pages. It was however already present before the projects were initiated both in the theoretical arguments shown above, as well in content editors' comments collected in the frame of this project (e.g., editors Bjerregaard, Poulsen, and Langguth), as well as in many of the editor statements collected by Thurman (2011). The two conflicting understandings may have their origin in different professional traditions (journalism versus ICT engineering), in different personal habits, values, and ideals that are projected on the design of systems and interfaces for media presentation, or in different organisational interests, e.g., between content producing departments and marketing-, distribution-, and strategic departments within the news organisation, in terms of the control over the exposure of the media content to users. Finally, the two understandings might reflect tensions between a quantitative way and a qualitative way of looking at performance and quality in media organisations. Further research however is needed to examine these hypotheses and their generalizability.

\section{Conclusion}

The editorial outcome of the experiments with customisable homepages and "my pages" appears to be a clearer focus on the inherent qualities in mass media recommendation. There is no big demand for a personalised service managed by the media brand, since the editorial recommendation seems more relevant for most users than the optimisation of individual attention economy (Simon, 1971; Mitchell, 2005). The individual filtering takes place beyond the control of the PSB, e.g., on content aggregator platforms, recommender services and in social media, or by simply not looking at or listening to the mass media content. From a PSB perspective, it has also become clear that the claimed individualisation of society does not necessarily mean that the presentation or marketing of the PSB products should be individualised. Instead, there seems to be a request for an identifiable and clear presentation of the PSB content that is based on a strong and reliable brand that is reflecting shared values more than individual preferences. It can be concluded that it is still the mass media product that stands in the middle, as a "social object" (Cetina, 1997). In this way, the customised PSB webpages have shown that the "public" of PSB, understood as the shared information space, has a higher importance for PSB users than the personal filtering. This is however not particular to PSB; also commercial mass media providing customised web services have discontinued their customised pages. Further, among the editors of the commercial media we observe sceptical positions towards customisation (Thurman, 2011), one that revolves around gate-keeping, the integrity of media brand, and the value of the knowledge of the human editor. These discussions are echoed by the PSB editors (except the first Mit DR editors). This indicates that it is the shaping of the editorial product and the strategic position of the PSB brand that is in their focus, rather than high-level normative 
discussions of PSB or PSM concept. Only when the activities appear to challenge or threaten actual stake-holders, e.g., commercial media or media politics, the editors explicitly relate to the high-level discussions. The PSB customisation projects seem thus not particularly constrained by media politics or normative discussions of the PSB or PSM concept. Instead they were practical attempts to adapt to the changing web market, as well as experiments with the meaning of the concept of PSM. As this research has shown, the editors however were wrong in their assumption of the rational and picky media user focussed on attention economy. Instead the projects demonstrated the social element in news: it is something that is known and shared by a group of people. The sharing just takes place on platforms not controlled by the mass media. The customisation projects thus help point out the important role of gate-keeping and editorial selection in a media landscape where it is easy for everyone to become a content recommender. At the same time, it is clear that if the policy goal is to ensure exposure of diversity of media content, this must be pursued on a higher level than a single media organisation (cf. Helberger, 2012, Sørensen, 2011).

\section{Acknowledgements}

The research presented above was conducted as a part of a PhD project at University of Southern Denmark 2007-2011, and published in Sørensen (2011). The author wishes to express his thanks to colleagues and supervisors at University of Southern Denmark, center for Media Science; and at Aalborg University, Copenhagen, center for Communication, Media and Information technology (CMI). Furthermore the author thanks Deutsche Telecom Design Research Laboratories, Berlin for fruitful inspiration. Finally, the author thanks all PSB practitioners contributing to this research project.

\section{Notes}

1 According to (LeMahieu, 1988: 145), Reith phrased in a speech July 1930: "The best way to give the public what it wants is to reject the express policy of giving the public what it wants". Quoted from (Bailey, 2007: 108)

2 The webpages of Sky News, Washington Post, Financial Times, The Guardian, The Mirror, New York Times, The Telegraph, The Sun, The Times Online, and The BBC News. See: (Thurman, 2011) for details.

3 www.netvibes.com and http://www.google.com/ig visited 2012-08-14

4 1) http://www.bbc.co.uk/ 2) http://www.rai.it/ 3) http://www.tvp.pl/ 4) http://tv2.rtp.pt/ 5) http:// www.srr.ro/ 6) http://bnr.bg/Pages/default.aspx 7) http://www.rtvslo.si/ 8) http://mein.wdr.de/beta/ 9) http://www.dr.dk/mitdr

5 http://www.dr.dk/mitdr, accessed latest 2013-03-05

6 http://www.dr.dk/mitdr as of 2011-01-31 
7 The News package”, "The Sports package”, "The Entertainment package”, “The Family package”, "The Lifestyle package", "The Overgrown Teenager's package" and "The Nerd package". www.dr.dk/mitdr/ igang, visited 2011-01-31

8 The non-customisable "Main Feature Box" triggered 88 negative users and only three positive comments on the web forum provided by the BBC to gather user-reactions. For example: "I like it a lot, but I want it to be FULLY customisable; I don't want this huge advert for the Live Lounge that I can't move about; I'm interested in news content, so naturally I want the news content at the top." (Daniel Bailey 08:01 PM, 14 Dec 2007);

"Please please either remove the "main feature" box at the top right of the homepage, or at least allow the user to customise it as we can do for the other boxes. It is too big and cumbersome and takes up over $50 \%$ of my screen without scrolling down. Not everyone has a wide screen and it just seems a vanity piece for the editorial team to tell us what to be interested in." (david guild 01:50 PM, 28 Feb 2008); “I despise the fact I can not remove the main feature. So I am condemned to stare at Anne Robinson.(...) I dislike the fact there is a "Customise your page" button that doesn't let you (fully) customise the page. You claim to have looked at Netvibes for inspiration. Well look again. Harder." (Andy C, 10:45 AM, 04 Mar 2008) source: http://www.bbc.co.uk/blogs/bbcinternet/2007/12/home_beta_page_response.html visited last time 2013-07-13

9 http://www.bbc.co.uk/blogs/bbcinternet/2008/01/editorial_content_on_the_new_h_1.html visited last time 2013-07-13

10 As of January 31,2011

11 http://fdim.dk/statistik/internet/toplisten accessed 2013-08-13

12 BBC: The BBC beta phase lasted from December 2007 to February 2008. The 390 BBC comments are placed on three blogs. The first blog opened December 13, 2007 at http://www.bbc.co.uk/blogs/ bbcinternet/2007/12/a_lick_of_paint_for_the_bbc_ho.html. In response to the comments, a new blog was launched December 21, 2007 at http:// www.bbc.co.uk/blogs/bbcinternet/2007/12/home beta_page_response.html. The latest entry is dated March 7, 2008. Finally, January 14, 2008 a third blog post was launched: http://www.bbc.co.uk/blogs/bbcinternet/2008/01/editorial_content_on_ the_new_h_1.html. The latest entry on this page is dated April 11, 2008. The webpages were accessed between December 2010 and January 2011.

Mit DR comments are distributed on three URLs aimed at three types of feedback: Technical problems, good ideas and general praise / criticism. 1): http://www.dr.dk/DRlogin/mitdr_feedback/ feedback (identical with http://www.dr.dk/DRlogin/mitdr_feedback/fejl.htm), 2): http://www.dr.dk/ DRlogin/mitdr/risros.htm 3) http://www.dr.dk/DRlogin/mitdr_feedback/ideer.htm Mit DR received in the period from June 2009 to January 12, 2011 in total 1098 comments. The webpages were accessed between December 2010 and January 2011.

Mein WDR: wdr.de/themen/global/hilfe/pers_homepage_meinung.jhtml (discontinued from 201108-10 as WDR.de introduced a new websystem). The webpage was accessed between December 2010 and January 2011, encompassing 151 comments.

13 http://www.bbc.co.uk/blogs/bbcinternet/2007/12/a_lick_of_paint_for_the_bbc_ho.html accessed several times, latest 2013-08-11

14 The eleven news webpages covered in the survey were: FT.com, NYTimes.com, TimesOnline.co.uk (now: .com), WallStreet)ournal.com, WashingtonPost.com, Guardian.co.uk, Mirror.co.uk, News.bbc. co.uk, News.sky.com, Telegraph.co.uk, theSun.co.uk. Of these, the first five featured a "my page" in the authors' survey Oct-Dec. 2010. The authors however overlooked that the BBC.co.uk homepage also offered customisation. 


\section{References}

Ali, K., \& van Stam, W. (2004). TiVo. In Proceedings of the 2004 ACM SIGKDD international conference on Knowledge discovery and data mining - KDD '04. New York, New York, USA: ACM Press. doi:10.1145/1014052.1014097

Anderson, C. (2004). The Long Tail. Wired. Retrieved from http://www.wired.com/wired/archive/12.10/tail. html

Ang, I. (1991). Desperately Seeking the Audience. London, New York: Routledge.

Bailey, Michael (2007). Rethinking Public Service Broadcasting: The Historical Limits to Publicness. In Richard Butsch (Ed.), Media and Public Spheres (pp. 96-108). electronic copy: Palgrave MacMillan.

Bakker, P. (2012). Expectations, Experiences \& Exceptions. Promises and Realities of Participation on Websites. In G.F. Lowe \& J. Steemers (Eds.), Regaining the Initiative for Public Service Media. (pp. 237-251). Göteborg: Nordicom, Göteborg Universitet.

Bechmann, A. (2009). Crossmedia: Innovationsnetværk for traditionelle medieorganisationer . Aarhus: Aarhus Universitet. PhD thesis.

Beck, U., \& Beck-Gernsheim, E. (2002). Individualization: Institutionalized Individualism and Its Social and Political Consequences. London, Thousand Oaks, Calif:: SAGE.

Beck, U., Vossenkuhl, W., \& Ziegler, U. E. (1997). Eigenes Leben : Ausflüge in die unbekannte Gesellschaft, in der wir leben. München: C.H. Beck.

Bredies, K., Joost, G., \& Chow, R. (2007). Designing Personalized Intelligent User Interfaces. IASDR 07 Conference. Hong Kong. Retrieved from http://www.sd.polyu.edu.hk/iasdr/proceeding/papers/Designing Personalized Intelligent User Interfaces.pdf

Brevini, B. (2009). Under siege by commercial interests? BBC and DR Online between the national and European policy frameworks. Interactions: Studies in Communication \& Culture, 1(2), (pp. 203-215). doi:10.1386/iscc.1.2.203_1

Carlson, M. (2006). Tapping into TiVo: Digital video recorders and the transition from schedules to surveillance in television. New Media \& Society, 8(1), 97-115. doi:10.1177/1461444806059877

Cetina, K.K. (1997). Sociality with Objects: Social Relations in Postsocial Knowledge Societies. Theory, Culture \& Society, 14(4), (pp. 1-30). doi:10.1177/026327697014004001

Chesnais, P.R., Mucklo, M. J., \& Sheena, J. A. (1995). The Fishwrap personalized news system. In Proceedings of the Second International Workshop on Community Networking "Integrated Multimedia Services to the Home" (pp. 275-282). Princeton, NJ: IEEE. doi:10.1109/CN.1995.509583

DR og Kulturministeren. (2006). Public service kontrakt mellem DR og kulturministeren for perioden 1. januar 2007 til 31. december 2010. Retrieved from http://www.kum.dk/graphics/kum/downloads/Kulturomraader/Radio_og_TV/Public Service kontrakt 2007/Publicservicekontraktennyudgave.pdf

DR. (2007). Strategic Goals. Retrieved May 14, 2008, from http://www.dr.dk/OmDR/About DR/20060622154614.htm

Fan, H., \& Poole, M. S. (2006). What Is Personalization? Perspectives on the Design and Implementation of Personalization in Information Systems. Journal of Organizational Computing and Electronic Commerce, 16(3-4), 179-202. doi:10.1080/10919392.2006.9681199

Graf, P. (2004). Independent Review of BBC Online. London: DCMS / Reckon. Retrieved from http:// go.reckon.co.uk/2jot

Harper, C. (1997). The Daily Me. American Journalism Review, April 1997. Retrieved from http://www.ajr.org/ Article.asp?id $=268$

Helberger, N. (2012). Exposure Diversity as a Policy Goal. Journal of Media Law, 4(1), 65-92. doi:10.5235/175776312802483880 
Ho, S.Y. (2006). The Attraction of Internet Personalization to Web Users. Electronic Markets, 16(1), (pp. 41-50). doi:10.1080/10196780500491162

Huizinga, J. (1955). Homo ludens : a study of the play-element in culture. Boston: Beacon Press.

Jakubowicz, K. (2006). Keep the Essence, Change (Almost) Everything Else: Redefining PSB for the 21st Century. In I. Banerjee \& K. Seneviratne (Eds.), Public Service Broadcasting in the Age of Globalization. AMIC - Asian Media Information and Communication Centre, Nanyang Technological University School of Commuication and Information.

Jakubowicz, K. (2007). Public Service Broadcasting in the 21st Century. What Chance for a New Beginning? In G.F. Lowe \& J. Bardoel (Eds.), From Public Service Broadcasting to Public Service Media (pp. 29-49). Kungälv: Nordicom, Göteborg Universitet.

Jauert, P., \& Lowe, G.F. (2005). Public Service Broadcasting for Social and Cultural Citizenship. Renewing the Enlightenment Mission. In P. Jauert \& G.F. Lowe (Eds.), Cultural Dilemmas in Public Service Broadcasting: RIPE@2005 (pp. 13-33). Göteborg: Nordicom.

Klapp, O.E. (1986). Overload and boredom: essays on the quality of life in the information society. New York: Greenwood Press.

Krippendorff, K. (2006). The semantic turn : a new foundation for design. Boca Raton: CRC/Taylor \& Francis. doi:10.1201/9780203299951

Kvale, S. (2007). Doing Interviews. Los Angeles, London, New Delhi, Singapore, Washington DC: SAGE.

LeMahieu, D.L. (1988). A Culture for Democracy: Mass Communication and the Cultivated Mind in Britain Between the Wars Oxford: Clarendon Press.

Livingstone, Sonia (2005). On the relation between audiences and publics. In Sonia Livingstone (Ed.), Audiences and publics: when cultural engagement matters for the public sphere (Vol. 2, pp. 17-42). Bristol, UK: Intellect Books.

Löblich, M. (2012). The battle for "expansion" of public service broadcasting on the Internet. The press coverage of the 12th amendment of the Interstate Treaty on Broadcasting and Telemedia in Germany. International Journal of Media \& Cultural Politics, 8(1), 87-104. doi:10.1386/macp.8.1.87_1

Lowe, G.F., \& Bardoel, J. (Eds.). (2007). From Public Service Broadcasting to Public Service Media. Göteborg: Nordicom.

Lowe, G.F., \& Jauert, P. (Eds.). (2005).Cultural Dilemmas in Public Service Broadcasting: RIPE@2005. Göteborg: Nordicom.

MacLean, A., Carter, K., Lövstrand, L., \& Moran, T. (1990). User-tailorable systems: pressing the issues with buttons. Proceedings of the SIGCHI conference on Human factors in computing systems Empowering people - CHI '90 (pp. 175-182). New York, New York, USA: ACM Press. doi:10.1145/97243.97271

Malik, Z.K., \& Fyfe, C. (2012). Review of Web Personalization. Journal of Emerging Technologies in Web Intelligence, 4(3), (pp. 285-296). doi:10.4304/jetwi.4.3.285-296

Mitchell, A. (2005). When it comes to media, power is still in the eye of the beholder. Marketing Week, 28(38), 30-31.

Moe, H. (2005). Television, Digitalisation and Flow : questioning the Promises of Viewer Control. Digital Utopia in the Media: From Discourses to Facts. A Balance (Proceedings). (pp. 773-785). Facultat de Ciències de la Communicació Blanquerna, Universitat Ramon Llull. doi:http://hdl.handle.net/1956/2150

Moe, H. (2008a). Public service broadcasting på internett? En komparativ analyse. In F. Mortensen (Ed.), Public service i netværkssamfundet (pp. 67-101). København: Forlaget Samfundslitteratur.

Moe, H. (2008b). Dissemination and dialogue in the public sphere: a case for public service media online. Media, Culture \& Society, 30(3), 319-336. doi:10.1177/0163443708088790 
Moe, H. (2008c). Public Broadcasters, the Internet, and Democracy Comparing Policy and Exploring Public Service Media Online. Department of Information Science and Media Studies. Bergen: University of Bergen.

Moles, A.A. (1968). Information theory and esthetic perception. Urbana: University of Illinois Press.

Murdock, G. (2005). Building the Digital Commons. Public Broadcasting in the Age of the Internet. In P. Jauert \& G.F. Lowe (Eds.), Cultural Dilemmas in Public Service Broadcasting : RIPE@2005 (pp. 213-230). Göteborg: Nordicom.

Negroponte, N. (1995). Being Digital. Vintage Books.

Nissen, C.S. (2006). No public service without both Public and Service - Content provision between the Scylla of populism and the Charybdis of elitism. In C.S. Nissen (Ed.), Making a Difference: Public Service Broadcasting in the European Media Landscape (pp. 65-82). Eastleigh: John Libbey Publishing.

Parks, L. (2004). Flexible Microcasting: Gender, Generation and Television-Internet Convergence. In L. Spigel \& J. Olsson (Eds.), Television after TV (pp. 133-156). Durham \& London: Duke University Press.

Parsons, A., Zeisser, M., \& Waitman, R. (1998). Organizing today for the digital marketing of tomorrow.Journal of Interactive Marketing, 12(1), 31-46. doi:10.1002/(SICI)1520-6653(199824)12:1<31::AID-DIR4>3.0.CO;2-X

Peppers, D., \& Rogers, M. (1993). The One to One Future: Building Relationships One Customer at a Time. New York: Currency Doubleday.

Petersen, A.B. (2008). Cross Media as Innovation Strategy: Digital Media Challenges in the Danish Broadcasting Corporation. RIPE@2008. Mainz. Retrieved from http://www.uta.fi/jour/ripe/papers/Bechmann Petersen.pdf

Picard, R.G. (2012). The Changing Nature of Political Case-Making for Public Service Broadcasters. In G.F. Lowe \& J. Steemers (Eds.), Regaining the Initiative for Public Service Media (pp. 27-44). Göteborg: Nordicom.

Ricci, F., Rokach, L., Shapira, B., \& Kantor, P.B. (Eds.). (2011). Recommender Systems Handbook. Boston, MA: Springer US. doi:10.1007/978-0-387-85820-3

Rosen, C. (2004). The Age of Egocasting. The New Atlantis, (Fall 2004 / Winter 2005), 51-72. retrieved from: http://www.thenewatlantis.com/publications/the-age-of-egocasting

Scannell, P. (1981). Music for the multitude? The dilemmas of the BBC's music policy, 1923-1946. Media, Culture \& Society, 3(3), 243-260. doi:10.1177/016344378100300304

Scannell, P. (1989). Public service broadcasting and modern public life. Media, Culture \& Society, 11(2), 135166. doi:10.1177/016344389011002002

Scannell, P. (2005). The Meaning of Broadcasting in the Digital Era. In P. Jauert (Ed.), Cultural Dilemmas in Public Service Broadcasting: RIPE@2005. Göteborg: Nordicom.

Schoenbach, K. (2007). "The own in the foreign": reliable surprise - an important function of the media? Media, Culture \& Society, 29(2), 344-353. doi:10.1177/0163443707074269

Shneiderman, B., \& Maes, P. (1997). Direct manipulation vs. interface agents. interactions, 4(6), $42-61$. doi:10.1145/267505.267514

Simon, H.A. (1971). Designing Organizations for an Information-Rich World. In M. Greenberger (Ed.), Computers, Communication, and the Public Interest (pp. 37-72). The Johns Hopkins Press.

Syvertsen, T. (2003). Challenges to Public Television in the Era of Convergence and Commercialization. Television \& New Media, 4(2), 155-175. doi:10.1177/1527476402250683

Sunstein, C.R. (2001). The Daily We - Is the Internet really a blessing for democracy? Boston Review. Retrieved from http://bostonreview.net/BR26.3/sunstein.html

Sunstein, C.R. (2007). Republic.com 2.0. Princeton Oxford: Princeton University Press.

Syvertsen, T. (1999). The Many Uses of the "Public Service" Concept. Nordicom Review, 1/1999. 
Sørensen, J.K. (2011). The Paradox of Personalisation: Public Service Broadcasters' Approaches to Media Personalisation Technologies. University of Southern Denmark (SDU). Available at: http://nordicom. statsbiblioteket.dk/ncom/da/publications/the-paradox-of-personalisation\%28e0d6ae05-2a6d-453e8a1b-72df8cf21457\%29.html (accessed last time 2013-11-19)

Thurman, N. (2011). Making "The Daily Me": Technology, economics and habit in the mainstream assimilation of personalized news. Journalism, 12(4), 395-415. doi:10.1177/1464884910388228

Thurman, N., \& Schifferes, S. (2012a). The Future of Personalization at News Websites. Journalism Studies, 13(5-6), 775-790. doi:10.1080/1461670X.2012.664341

Thurman, N., \& Schifferes, S. (2012b). The Paradox of Personalisation: The Social and Reflexive Turn of Adaptive News. In E. Siapera \& A. Veglis (Eds.), The handbook of global online journalism (pp. 373-391). Malden, Mass.: Wiley-Blackwell.

Trappel, J. (2008). Online Media Within the Public Service Realm?: Reasons to Include Online into the Public Service Mission. Convergence, 14(3), 313-322. doi:10.1177/1354856508091083

Velusamy, S., Gopal, L., Bhatnagar, S., \& Varadarajan, S. (2008). An efficient ad recommendation system for TV programs. Multimedia Systems, 14(2), 73-87. doi:10.1007/s00530-008-0117-1

Vesanen, J. (2007). What is personalization? A conceptual framework. European Journal of Marketing, 41(5/6), 409-418. doi:10.1108/03090560710737534

Victor, B., \& Boynton, A.C. (1998). Invented Here. Boston, Massachusetts: Harvard Business School Press.

\section{List of interviews}

MitDR

Jens Poder, dr.dk Chief Editorial Board, first Mit DR editor:

\#1: May 3, 2007

\#2: September 13, 2007

\#3: November 13, 2007

\#4: June 17, 2008 (Poder left DR February 2008)

Christian Valentiner, DR Interactive Production, Project leader of Mit DR, then second Mit DR editor:

\#1: March 14, 2008 (with developer Simon H. Nielsen)

\#2: June 11, 2008 (with developer Simon H. Nielsen)

\#3: October 1, 2008

\#4: January 15, 2009

\#5: June 3, 2009

Mikkel Pagh, third Mit DR editor:

January 24, 2011

Niels Prætorius, dr.dk channel editor:

June 19, 2008

\section{Mein WDR}

Thomas Drescher, editor Mein WDR / WDR.de:

November 30, 2010 
Article: Public service broadcasting goes personal

\section{BBC}

James Price, Editor of the customisable homepage:

March 25, 2011

Other PSB editors:

DR - Denmark

Henrik Heide, Editor dr.dk streaming radio:

May 29, 2007

Thomas Hertz, DR Head of Marketing:

March 11, 2008

Ernst Poulsen, dr.dk Chief Editorial Board, Editor News:

January 20, 2009

Louise Bjerregaard, News Editor, DR-Update:

October 18, 2007

Kristian Stokholm, Project Leader, Web Production, Aarhus branch of DR:

October 23, 2008

Thomas Dose, DR Musik \& Medier (email interview):

June 9, 2009

\section{Germany}

\section{Rundfunk Berlin Brandenburg (RBB)}

Frauke Langguth:

\#1: as Editor in Chief, rbb Internet: November 11, 2007

\#2: as Head of ARD Text TV, July 4, 2008

Oliver Gerstner, Programmcontrolling Fernsehen, rbb: March 27, 2008

Björn Stockleben, Project Engineer, rbb Innovation:

\#1: February 27, 2008

\#2: February 9, 2009

\section{ARD}

Sabine Schade, Redaktion CvD, ARD-Mediathek:

September 5, 2007

Alessandra Crivellaro, Das Erste Mediathek:

September 5, 2007

\section{ZDF}

Jürgen Kleinknecht, Editor, ZDF New Media:

October 29, 2008

Thomas Waldner, Editor, ZDF New Media (two interviews)

\#1: May 30, 2007

\#2: June 5, 2008

Hendrik von Sprechelsen, Developer, ZDF-Mediathek:

September 4, 2007 
Article: Public service broadcasting goes personal

UK

BBC

Silvia Costeloe, Editor BBC Blast, BBC: October 18, 2007 John Partington, New Media Editor, BBC:

October 24, 2008

Peter Harvey, Producer - Multiplatform, Innovation and Development Studio, BBC:

October 24, 2008

\section{Finland}

Marja Honkakorpi, Head of New Media Concept Design, YLE:

October 23, 2008

\section{Slovenia}

Zvezdan Martic, Head of Multimedia Centre, RTV Slovenija:

\#1: October 18, 2007

\#2: August 5, 2009

\section{The Netherlands}

Ad van der Ree, Chief editor, New Media, VARA:

October 18, 2007

Maarten Siffels, Digital Media / Creative Director, KRO:

October 18, 2007

\section{Switzerland}

Samuel Vuillermoz, Developer, M×3.de, SRG SSR ideé Suisse:

October 23, 2008

Jannick Kirk Sørensen

Assistant Professor, PhD

Center for Communication, Media and Information Technologies (CMI) Aalborg University, Denmark js@cmi.aau.dk 